\title{
Effect of exercise and physiotherapy in aiding sputum expectoration in adults with cystic fibrosis
}

\author{
W SALH, D BILTON, M DODD, A K WEBB \\ From the Regional Adult Cystic Fibrosis Unit, Monsall Hospital, Manchester
}

\begin{abstract}
The role of exercise in aiding sputum expectoration in patients with cystic fibrosis and the comparative roles of exercise and physiotherapy in sputum expectoration were assessed in two studies. In the first study 19 adult patients undertook a two month programme of home exercise using a cycle ergometer. In the 12 patients completing the study peak work capacity, maximum oxyger? consumption, and maximum minute ventilation had increased significantly by the end of the exercise programme; the increase in daily sputum weight (from 24 to $37 \mathrm{~g}$ ) was not significant ( $\mathrm{p}=0.055)$. In? the second study (with 10 patients) more sputum was expectorated during and after physiotherapye than during and after exercise $(9.8 v 4.0 \mathrm{~g})$. Exercise may have a role in aiding sputum expectoration in patients with cystic fibrosis but should not be considered as a replacement for physiotherapy.
\end{abstract}

\section{Introduction}

The importance of exercise as part of the management of patients with cystic fibrosis has been much emphasised. Swimming has been shown to improve forced expiratory volume and increase sputum clearance. ${ }^{1}$ A three month exercise programme improved cardiorespiratory fitness and respiratory muscle endurance ${ }^{2}$ and a regular home exercise programme reduced breathlessness independently of ventilation. ${ }^{3}$ In that study, as in others, ${ }^{45}$ there was also a reduction in the patients' residual volume, suggesting a reduction in trapped gas by opening up closed bronchi and collateral airways. It has been suggested that chest physiotherapy can be replaced by exercise, ${ }^{45}$ though there are few data showing a beneficial effect of exercise on sputum expectoration. We have investigated the effect of a home exercise training programme in aiding sputum expectoration and have compared the sputum clearance produced by exercise and physiotherapy.

\section{Methods}

STUDY 1

Nineteen patients with cystic fibrosis, mean age 21 (range 16-32) years, were recruited on the basis of their

Address for reprint requests: Dr A K Webb, Monsall Hospital, Manchester M10 8WR.

Accepted 21 September 1989 willingness to take part in the study. All were studied $\vec{\oplus}$ when well and six weeks after a previous course of $^{\circ}$ antimicrobial chemotherapy. In all cases the lungs were colonised by Pseudomonas aeruginosa. At tres beginning of the study each patient collected thre days' expectorated sputum and the daily weight was calculated. Each patient underwent a maximal pro- $\mathbb{\perp}$ gressive exercise test with one minute increments on an $\overrightarrow{\vec{A}}$ electronically braked cycle (Corival 300 ). Measure- $\frac{}{3}$ ments were made of peak work capacity, maximum oxygen consumption, and maximum minute ventila-o. tion. Body weight and $\mathrm{FEV}_{1}$ and FVC were also determined.

All subjects received a Tunturi exercise cycle $\underset{\times}{\overrightarrow{0}}$ for home use.' They were instructed to perform $10 \dot{0}$ minutes' exercise five days a week, starting at $50 \%$ of the peak work capacity determined at their initialo progressive exercise test. When comfortable at a₹ particular load they were instructed to increase the응 work rate on their cycle by 5 watts up to once a week. $>$ At the end of two months' training the three days' totalo sputum collection and progressive maximal exercise test were repeated. Compliance was assessed from a ${ }^{\circ}$ diary kept by the patient. The patients' home ${ }^{\text {O }}$ physiotherapy continued throughout the study.

\section{STUDY 2}

Ten further patients, mean age 21 (range 16-33) years, again with $P$ aeruginosa colonisation, were studied? while in hospital because of a respiratory exacerba- $\square$ tion. They were assessed on four days during the lasto week of their hospital stay and at the same time of day. 
Table 1 Mean (SD) values of peak work capacity (PWC), maximum oxygen consumption ( $\dot{V}_{2}$ max), maximum minute ventilation (MMV) before and after a two month home exercise cycle training programme in 12 patients

\begin{tabular}{lccr}
\hline & Before & \multicolumn{1}{c}{ After } & \multicolumn{1}{c}{$p$} \\
\hline PWC $(\mathrm{W} / \mathrm{kg})$ & $2.71(0.415)$ & $3.14(0.48)$ & 0.003 \\
$\dot{\mathrm{VO}}_{2} \mathrm{max}$ & & & \\
$(\mathrm{ml} / \mathrm{kg} / \mathrm{min})$ & $25.9(4.25)$ & $30.3(4.15)$ & $<0.001$ \\
$\mathrm{MMV}(\mathrm{l} / \mathrm{min} / \mathrm{kg})$ & $0.88(0.15)$ & $1.04(0.16)$ & 0.004 \\
\hline
\end{tabular}

At the start of a four hour study period the subjects underwent either 15 minutes' chest physiotherapy (a forced expiration technique plus postural drainage) or 15 minutes' cycling at $50 \%$ of their peak work capacity. All sputum expectorated during each of these procedures and during the next 1.75 hours was collected and weighed. At the end of two hours they received the alternative regimen. The study was repeated on four consecutive days, exercise being the starting regimen on two days and physiotherapy on the other two.

\section{STATISTICAL ANALYSIS}

Paired $t$ tests were used to analyse differences in the exercise data. The Wilcoxon matched pairs test was used for comparing the weights of the sputum produced in both studies.

\section{Results}

STUDY 1

Twelve patients completed the first study; five patients had infective exacerbations and two failed to comply with the study requirements as they did less than three exercise sessions a week at home. The patients completing the study felt better subjectively after the training period.

Table 2 Mean daily weight of sputum expectorated over three days before and at the end of a two month home exercise programme

\begin{tabular}{|c|c|c|c|}
\hline \multirow{2}{*}{$\begin{array}{l}\text { Patient } \\
\text { No }\end{array}$} & \multirow{2}{*}{$\begin{array}{l}F E V_{1} \\
\text { (\% pred) }\end{array}$} & \multicolumn{2}{|c|}{ Sputum weight (g/day) } \\
\hline & & Before & After \\
\hline $\begin{array}{r}1 \\
2 \\
3 \\
4 \\
5 \\
6 \\
7 \\
8 \\
9 \\
10 \\
11 \\
12\end{array}$ & $\begin{array}{l}25 \\
68 \\
66 \\
33 \\
15 \\
44 \\
78 \\
67 \\
94 \\
71 \\
27 \\
32\end{array}$ & $\begin{array}{r}89 \\
14 \\
43 \\
8 \\
40 \\
10 \\
<5 \\
<5 \\
<5 \\
<5 \\
40 \\
24\end{array}$ & $\begin{array}{r}162 \\
32 \\
97 \\
22 \\
50 \\
15 \\
<5 \\
<5 \\
<5 \\
<5 \\
38 \\
13\end{array}$ \\
\hline
\end{tabular}

$p=0.055$ for the comparison of sputum weight before and after a home exercise programme.

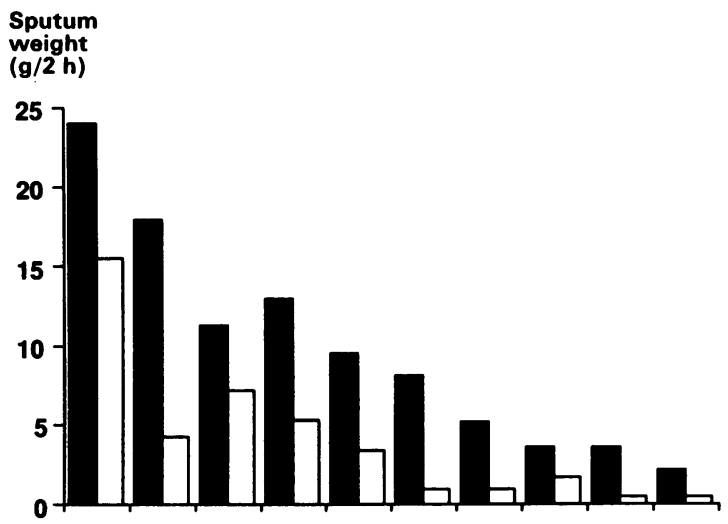

Weight of sputum expectorated during physiotherapy ( $\square$ ) and exercise ( $\square$ ) in 10 patients. Significantly more sputum was produced during physiotherapy $(p<0.01)$.

There were no significant changes in body weight or in $\mathrm{FEV}_{1}$ or FVC at the end of the study. There was a significant increase in peak work capacity, maximum oxygen consumption, and maximum minute ventilation (table 1).

The mean (SD) daily sputum output was $24(25 \cdot 3) \mathrm{g}$ at the beginning of the exercise programme compared with $37.4(47.4) \mathrm{g}$ at the end; the difference was not significant $(\mathrm{p}=0.055$ : table 2$)$.

STUDY 2

All patients produced more sputum during the physiotherapy period (mean (SD) $9.8(7.0) \mathrm{g}$ ) than during the exercise period $(4.0(4.6) \mathrm{g}$; $\mathrm{p}<0.01$ : figure). No order effect was seen when the data were analysed according to whether exercise or physiotherapy was the initial procedure.

\section{Discussion}

Over the years the techniques of physiotherapy used for cystic fibrosis patients have been refined and the benefits studied. ${ }^{6}$ As patients enter adolescence, however, compliance may decrease, particularly with a rigorous daily regimen of postural drainage. ${ }^{7}$ Exercise may be pleasurable and is of benefit to patients with chronic airflow limitation. ${ }^{8}$ Similar studies in cystic fibrosis patients have shown considerable improvement in cardiopulmonary fitness ${ }^{29}$ and some patients have completed marathons. ${ }^{10}$

Some studies have suggested that arduous exercise may replace physiotherapy. ${ }^{14}$ This claim was based on the finding that when patients with cystic fibrosis stopped physiotherapy during a training programme there was no deterioration in lung function during the period of the exercise study; but there have been few studies assessing the effect of exercise on sputum 
expectoration or the relative contribution of physiotherapy and exercise to sputum production.

Our first study showed that during a strenuous but safe home exercise programme many of the patients with severe lung disease increased their sputum expectoration, though overall the increase was not statistically significant. As deteriorating lung function in such patients may be related to retention of infected sputum, it might be reasonable to recommend home exercise programmes for these patients.

Our second study suggests that this should not be at the cost of daily physiotherapy. In this study physiotherapy was more effective than exercise in inducing sputum expectoration. The possible reasons for this are that exercise and eucapnic hyperventilation accelerate mucociliary transport, " but exercise is not as effective as coughing in producing peripheral clearance of mucus. ${ }^{12}$ Chest physiotherapy for patients with cystic fibrosis comprises postural drainage with the forced expiration technique (FET), breathing exercises, and coughing, with the FET being aimed specifically at mobilising secretions from peripheral airways. An explanation for the different recommendations from other studies, that exercise can replace physiotherapy, may be due to the different populations studied. Our patients were adults chronically colonised with Pseudomonas aeruginosa and differed considerably from children with well preserved lung function, who are less likely to be colonised with Pseudomonas aeruginosa ${ }^{5}$.

Exercise undoubtedly provides considerable cardiovascular and respiratory benefits ${ }^{2-59}$ and might aid sputum expectoration. Physiotherapy and exercise should be considered as complementary rather than exclusive in the treatment of cystic fibrosis.

WS and DB were supported by the Cystic Fibrosis Trust. We thank Drs S Hanley and P O'Neill for helpful criticism.

\section{References}

1 Zach MS, Purrer B, Oberwaldner B. Effect of swimmingo on forced expiration and sputum clearance in cystico fibrosis. Lancet 1981;ii:1201-3.

2 Orenstein DM, Franklin BA, Doershuk, et al. Exercise conditioning and cardiopulmonary fitness in cystic fibrosis. Chest 1981;80:392-8.

3 O'Neill P, Dodd M, Phillips B, Poole J, Webb AK. Regular exercise and reduction of breathlessness in patients with cystic fibrosis. $\mathrm{Br} J$ Dis Chest $1987 ; 81:$ $62-9$.

4 Andreasson B, Jonson B, Kornfalt R, et al. Long-term $\overrightarrow{\vec{\sigma}}$ effects of physical exercise on working capacity and pulmonary function in cystic fibrosis. Acta Paediatr $\perp$ Scand 1987;76:70-5.

5 Zach M, Oberwaldner B, Hausler F. Cystic fibrosis ${ }^{+}$ physical exercise versus chest physiotherapy. Arch Dis응 Child 1982;57:587-9.

6 Pryor JA, Webber BA, Hodson ME, Batten JC. Evalua-윽 tion of the forced expiration technique as an adjunct topostural drainage in treatment of cystic fibrosis. $\mathrm{Br}$ Med J 1979;ii:417-8.

7 Currie DM, Munro C, Gaskell D, Cole PJ. Practice, $\stackrel{\mathbb{Q}}{\square}$ problems and compliance with postural drainage: aO survey of chronic sputum producers. Br J Dis Chest 1986;80:249-55.

8 Mungall IP, Hainsworth R. An objective assessment of the value of exercise training to patients with chrogic obstructive airways disease. $Q J$ Med 1980;193:77-85.

9 Cropp GJ, Pullano TP, Cerny FJ, Nathanson IT. Exercise tolerance and cardiorespiratory adjustments $\frac{G}{4} \mathrm{t}$ peak work capacity in cystic fibrosis. Am Rev Respirñ Dis 1982;126:211-20.

10 Stanghelle JK, Skyberg D. Cystic fibrosis patients running a marathon race. Int $J$ Sports Med 1988;9:37-40. 응

11 Oldenburg Jnr FA, Dolovich MB, Montgomery JM, Newhouse MT. Effects of postural drainage, exercise and cough on mucus clearance in chronic bronchitis Am Rev Respir Dis 1979;120:739-45.

12 Wolff RK, Dolovich MB, Obminski G, Newhouse MT으 Effects of exercise and eucapnic hyperventilation on bronchial clearance in man. J Appl Physiol: Respiro Environ Physiol 1977;43:46-50. 